\title{
Peculiarities of implementing mechanism of circular economy in the context of sustainable development of communities
}

\author{
Volodymyr Khymynets ${ }^{1}$, Anatolii Holovka ${ }^{1 *}$, and Ganna Tsimbolynets $^{2}$ \\ ${ }^{1}$ National Institute for Strategic Studies, Department for Research of the Western Region, 10 Zahorska \\ Str., 88000 Uzhhorod, Ukraine \\ ${ }^{2}$ Uzhhorod National University, Department of International Economic Relations, 3 Narodna Sq., \\ 88000 Uzhhorod, Ukraine
}

\begin{abstract}
The article analyzes prospects for implementing mechanisms of closed-loop economy (circular economy) at local level based on strengthening material and financial base of communities, expanding their managerial powers due to decentralization. Relevant changes in the approaches to form communities' socio-economic sphere aimed at gradual transition to circular economy have been pointed out, as well as main priorities in the framework of such transition are identified and characterized. Main directions and measures are suggested, which are aimed at achieving resource efficiency, waste processing, using secondary raw material and minimizing environmental damage in the framework of social and economic activities. Methodological principles for the study were methods of system analysis (to analyze circular economy as holistic system of interconnected elements with specific functions), generalization (to outline main directions and applied propositions for implementing circular economy at the level), comparison (to compare linear and circular models of economy).
\end{abstract}

\section{Introduction}

Positive consequences of reforming local self-government and territorial authority organizations in terms of expanding budget and administrative capacity of territorial communities have created conditions for disclosure of their internal potential, as well as contributed to intensification of economic activity at the local level. At the same time, mentioned reform also showed that success of a particular community in ensuring stable economic growth and high-quality indicators of population life in many ways depends on efficient use of available resources in communities, responsible waste management and environmental protection. This proved that local communities can become a basic link in transition from traditional linear model of economy to the model of "closed-loop economy" - a circular economy.

\footnotetext{
*Corresponding author: holovka.niss@gmail.com
} 
It is also worth mentioning that practical implementation of mechanisms of circular economy (in particular at local level) is an integral part of European developed countries agenda, which is justified, firstly, by defining certain goals in program and strategic documentation (it includes, in particular, Action Plan on Circular Economy adopted by European Commission on 11 March 2020, as well as a number of documents adopted at the level of individual European countries), secondly, by significant support from EU funds in the form of investments and grants for specific business projects and startups related to rationalization of waste management, stimulating development of waste processing industry, bioeconomy, transition to usage of renewable energy sources, etc. In the context of Ukraine's European integration aspirations, it is worth studying European economic policy, as well as adopting the most successful economic practices, in particular in terms of implementing mechanisms for development of circular economy.

\section{Theory}

Broadly speaking, the difference between linear and circular economy models lies in different approaches for using resources: if the first model is based on the approach to production, operation and subsequent disposal of a particular product, then the second model is based on reducing resource use and resource efficiency, as well as on implementing into production process mechanisms, which will contribute to reuse (multiple use) of waste and recyclables (and, as a result, will reduce negative impact on the environment). Within the concept of closed-loop economy, the "circular" principle "3-R" reduce, reuse, recycle or "reduction, reuse, recycling" is opposed to the traditional "linear" principle of "take-make-dispose" (Fig. 1) [1].

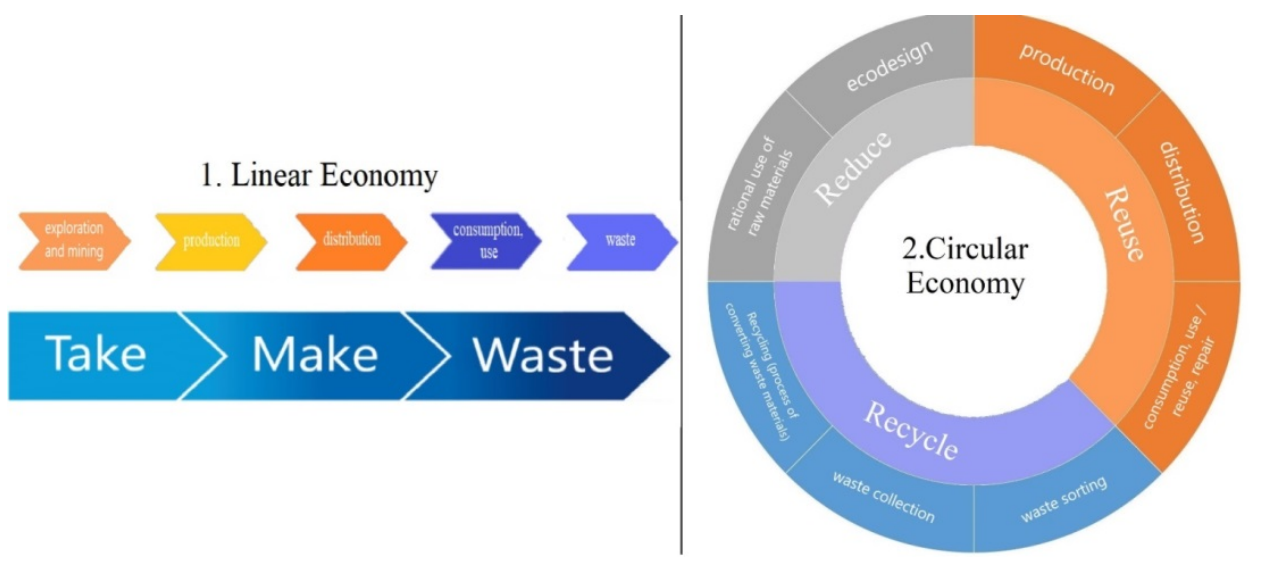

Fig. 1. Differences between linear (1) and circular (2) economy.

Model of circular economy uses two types of cycles: the first type of cycles of organic or biological materials able to return to biosphere without harming nature; the second type of cycles of technical materials, which should be kept in circulation as long as possible with the help of such tools as rent, modification, repair, processing and re-production, reuse [2].

It should be specially noted that in the framework of circular economy implementation, role of direct consumers of goods and services is important - it is not just about giving preference to environmentally friendly products (i.e. goods made from recycled materials, and vice versa, abandonment of non-recyclable goods), but also about direct participation in functioning of closed cycle mechanisms, for example, be means of waste sorting, their provision for processing, etc. [11]. 


\section{Methods}

Paper research has required using a number of scientific methods. That means using method of system analysis of circular economy model as integral system of interconnected elements (specifically economic tools which are alternative in relation to traditional tools of linear economy) with specific functions, the most important of them are (1) reducing negative anthropogenic and technogenic impact on the environment, as well as (2) rational management of available natural resources. Method of comparison is also used in order to compare key principles of linear and circular (closed-loop) economy models. In terms of defining main directions and practical proposals for implementing mechanisms of circular economy at the level of territorial communities, method of generalization has been applied.

\section{Discussion}

Ukraine's economy has been facing significant difficulties in recent years and requires urgent renovation and investment. This formulated relevant national priorities for socioeconomic development - increasing level of investment attractiveness, supporting enterprises, promoting job creation, etc. At the same time, implementation of measures to restore economic growth may have potential risks for the country, including excessive resource exploitation and environmental pollution [9]. Thus, in particular, L. Sergienko points out that tendency of worsening environmental problems is mainly due to economic processes and usage of traditional economic model, which is inefficient in terms of negative impact on the environment (and therefore on human life) and cannot be used in the framework of sustainable development [4].

Taking into account above-mentioned theses, application of resource efficient and ecosystemic approaches in view of economic policy is becoming increasingly relevant. A. Zelinska points out that in the context of implementation of circular economy mechanisms it is important to go beyond traditional tools of market environment management, which should support development of services and new business models aimed at production rationalization and waste reduction / reuse [12].

For Ukraine, issue of resource efficiency and minimization of harmful effects on the environment is an urgent issue and is currently beginning to be considered at the highest state level. In modern conditions, dominant method of solid waste management in Ukraine is their removal and disposal at landfills, as well as their accumulation in landfills (including natural landfills). On average, only $5-7 \%$ of waste generated in Ukraine is processed, incinerated or composted every year. Most of the waste is brought to already mentioned landfills and dumps, the third part of which do not meet environmental and sanitary safety standards, and some of them are generally overloaded (not to mention forests and rivers pollution with solid waste) [6].

All this indicates not only irrational use of available resources and irresponsible waste management, but also the fact that significant amounts of raw materials remain unused. In addition, there are no opportunities to create new jobs and attract investment to construction and infrastructure facilities that would ensure safe processing and / or utilization of solid waste.

To solve given issues step by step, in 2017 the Cabinet of Ministers of Ukraine approved National Waste Management Strategy in Ukraine until 2030, which reflected goals of transition to closed-loop economic processes, which leads to multiple and as long as possible use of materials and resources in production process, reduction of waste volumes. In view of this, strategy pays considerable attention to the process of processing solid waste and its return (or return of their components) to the production process as secondary raw material or as secondary energy resource (so-called "energy recovery"). 
Even though creation of special strategic document dedicated to rationalization of waste management based on circular economy is a significant step at national level, no less important is practical implementation of certain public policy objectives, especially at local level. And in this context, local communities will be able to become one of the main entities that have potential to "relay" ideas of circular economy into socio-economic sphere and, most importantly, their practical implementation. As it has been mentioned at the beginning of this paper, with the help of strengthening financial and material base of communities and their authority expanding in terms of available resources and budget management, it is appropriate to speak about opportunities to optimize and improve existing mechanisms of economic activity (which is often based on passive exploitation of available natural resources, obsolete resource- and energy consuming production processes), which will not only increase productivity indicators (as some resources will be reused and used as long as possible), but also life quality of community residents.

Circular economy can enable cities, towns and villages and their unions - local communities, to use their internal potential to solve key social, environmental and economic problems. Responsible management of organic waste and other activities, together with study of new consumption patterns, can provide practical measures to reduce waste, create new jobs, strengthen existing and create new centers of economic activity, as well as improve environment condition and population welfare [10].

\section{Results}

Local communities should use limited resources rationally and achieve production efficiency (especially if we are talking about underdeveloped or depressed areas), which will simultaneously help solve the most pressing problems (such as problems with waste accumulation and lack of environmentally friendly mechanism for recycling / recovery).

Considering above mentioned arguments, it is relevant to change the approaches forming socio-economic sphere of communities in order to ensure priority of such economic and social activities that minimize waste, as well as ensure restoration and rational consumption of available natural resources.

In this context three key priorities might be followed:

1) Ensuring rational use of resources and their restoration - under the conditions of strengthening financial base of communities and their economic activity, it is important to achieve resource efficiency. Irrational use of community resources for business processes can lead to either loss of business opportunities or significant waste accumulation. In the given context, it is important to develop an algorithm for practical steps to organize economic processes on "cascade principle" - principle suggested within the framework of "blue economy" concept by Günther Pauli, using which all production processes involve cascading nutrients, where waste from each production process stage become raw materials for the next one [2]. Such production models can be even more profitable than the main primary business - new jobs are created, there are no problems raw meterials shortage, environmental pollution and waste dumping.

2) Rationalization of waste management - gradual ending of recyclable waste dumping. This priority correlates with necessity to solve so-called "garbage crisis" problem, which is acute for communities and regions of Ukraine. The problem of irrational waste management that has already been mentioned, causes such negative consequences in Ukraine as congestion of landfills and dumps, their non-compliance with sanitary and environmental requirements, formation of natural dumps and environmental pollution. Transcarpathian region is given as an example - population of this region is about 1.25 million people and annually produces about 300 thousand tons of waste. However, existing waste dumps and landfills are loaded by more than $80 \%$, process of construction and 
operation of waste processing plants is still far from completion (waste processing plant in the village of Yanoshi, Beregovo district, which potentially can process 20-30 thousand tons of garbage annually, has not yet started operating due to lack of funds).

3) Minimization of harmful effects on environment is directly related to the first two priorities and should be based on the principles of rational use of available resources to meet society needs, without creating a threat for future generations and environment.

Achieving mentioned above three priorities will require a number of organizational steps at local level (providing general coordination of central executive bodies) in the following areas:

- Using potential of public-private partnership and government-community interaction in the framework of implementation of circular economy principles. Establishing partnership on a mutually beneficial basis between local authorities (local governments and their executive departments), on the one hand, and local businesses, on the other, will not only increase human and resource capacity for circular economy, but also strengthen mutual trust between participants and increase their social responsibility.

At local level, this involves interaction between government and entrepreneurs in the process of implementation of community-demanded business initiatives to organize collection, transportation and shipment of solid waste (which should be preceded by organizational actions to provide sorting containers for government agencies, educational institutions, local businesses, etc.). Among the tools for practical implementation of such business initiatives at community level (in most cases there might be a lack of material and technical conditions for this) it is appropriate to mention leasing - receiving equipment for future usage from leasing company (special plant and machinery, equipment, inventory, etc.). necessary to ensure process of solid waste collection, transportation and even processing.

It is also important for local authorities and business representatives to agree on measures to implement principles of "zero waste" within activities of establishments selling food and industrial goods, i.e. principles of minimum (or even deficiency) of waste gradual reduction and / or rejection of goods and objects, which are not recyclable (for example, rejection of disposable plastic bags in favor of reusable fabric or "bio-bags", which are made from compost raw materials and are gradually biodegradable).

In this context, it is important for the government to determine, in accordance with procedure established by law, tax benefits and other preferences for enterprises whose activities relate to processing of solid waste and secondary raw materials.

At level of local communities, it is appropriate to consider possibility of exemption above mentioned enterprises from rent for utility facilities or other premises which are necessary for their operating and location of machinery and equipment owned by community.

On the individual base provision should be made for granting tax benefits for enterprises whose activities do not involve recycling of waste or secondary raw materials, but who make conditions for solid waste sorting or reuse.

In the framework of government-community interaction (i.e. interaction between public authorities, local governments, on the one hand, and civil society, on the other), implementation of the following steps is important:

- inclusion of community activists and volunteers into relevant working groups established at local councils;

- joint activity on conducting public educational events, informational and explanatory work with population (at schools, enterprises, government establishments);

- interaction with volunteers, who express their intention to work on voluntary basis for joint mass actions and implementation of social initiatives demanded by the community (for example, within organizing waste paper collection, glass containers, plastics, etc.). 
In particular, it should be highlighted that it is appropriate to involve representatives of scientific and expert community and regional development agencies, experts with experience in project management to raise funds for international technical assistance, cross-border and territorial cooperation programs, State Fund for Regional Development, state targeted programs, etc.

- Implementation of incentives actions for population. Providing funding for projects and initiatives. As practice shows, profit from selling sorted household waste is not able to cover costs of sorting garbage. To solve this problem, it is necessary to implement financial incentives for population in order to encourage them to sort solid waste.

This refers to establishing for communities' residents (for example at level of condominium associations) norms at which in case of sorting solid household waste they will be released from payment for its removal (expenses of the enterprise engaged in sorted waste removal will be covered from local budget).

In collaboration with NGOs and volunteers, it is appropriate to create crowdfunding platforms (i.e. funds through which voluntary contributions are collected) to organize public funding for projects and initiatives related to rationalization of solid waste management and resource efficiency.

It is important to create a target fund focused on investing and providing grants for business initiatives and startups that are related to modernization and optimization of production processes in closed-loop economy. Target fund's capital is appropriate to form with the help of (1) obligatory share of funding from the State Budget of Ukraine, (2) international technical assistance from international donor organizations, (3) donations from private donors.

- Influence on educational and scientific sectors. Strengthening the role of local communities in education not only expands their direct responsibilities, but also creates new opportunities, in particular in the context of "retransmission" of knowledge about circular economy advantages over linear economy, as well as promoting the idea of reducing negative environmental impact.

Within educational institutions activities, it is important to hold seminars, trainings and other events that would be devoted to resource-efficient and "clean" production, responsible waste management in the context of sustainable community development.

It is particularly important to define importance of universities and other higher education institutions, which are intellectual potential kernel of the region and are able to produce relevant research. Considering this it is necessary to carry out the following organizational actions under general coordination of Ministry of Education and Science of Ukraine: (1) creating new and adjusting existing curricula, (2) using specific forms of interaction "science-business" (science parks and business incubators, business centers and startup centers at universities) to conduct research, bring their results and research to the level suitable for commercialization, (3) promoting cooperation between higher education institutions, research institutions in the framework of joint research and exchange of experience.

- Activization of inter-municipal cooperation. In this context, it is also important to use opportunities for inter-municipal cooperation within the framework of common development goals of two or more communities. One of the most prospective lines of such cooperation is setting up process of collection and processing / disposal of solid waste by combining common budgetary, organizational and human capabilities on contractual basis (i.e. by concluding appropriate agreements on cooperation in certain areas). For example, waste collection and disposal machines can replace each other in neighbour local communities in case of necessity or failure, and communities do not need to keep more spare equipment. 
Inter-municipal cooperation in this area will not only attract additional resources and focus on solving common problems, but will also have positive impact on investment, local business development and infrastructure.

In addition, forming stable relationships between communities is possible by creating points of economic growth of cluster type (clusters) - concentration of enterprises that work closely together (within production of goods, services, business transactions, etc.) and geographically located in a small area (for example, within two or more communities). Clusters based on networking between its members create a unique institutional environment that increases level of trust between them and allows them to solve common problems better (including negative environmental impact, waste management, etc.). In addition, clustered enterprises are more resilient to existing challenges, recover faster after economic crises compared to economy of the region as a whole, as well as increase employment and diversification, improve environmental efficiency [8].

- Including circular economy goals into local development strategies. A particular aspect that should be mentioned is requirement to implement concept of circular economy in local development strategies and programs. It refers to importance of defining certain strategic and / or operational goals among community development strategies, which would reflect focus on implementation of closed-loop mechanisms into economic activities at local level.

In addition, it is important to ensure coherence, compatibility and complementarity of strategic and operational goals of local strategies and development programs with the basic principles of National Waste Management Strategy (in the context of transition to closedloop economy).

In short term perspective, implementation of above-mentioned steps and adjustment of local development strategies and programs will lead to appropriate changes in local community development budgets, as well as in regional budgets.

\section{Conclusions}

Positive consequences of reforming local self-government and territorial organization of authorities in Ukraine have created additional opportunities for implementing principles of resource efficiency and reducing waste at level of local communities, which can be considered as one of preconditions for transition of Ukrainian economy to closed-loop model. However, rational use of such opportunities depends on implementation of sciencebased approaches in the framework of economic entities operation at community level, as well as systemic policies and coordination by central executive bodies.

Undoubtedly, favorable factor in this context is expansion of managerial and budgetary power of communities, which should be considered as institutional basis for implementing new economic approaches that would ensure stability of socio-economic growth and minimize anthropogenic and technogenic environmental impact at local level. In this context, an integrated approach is becoming essential, which would include changes to local development strategies, initiation of interregional projects, active interaction with local business and potential investors, development agencies, community activists, volunteers.

As a result, goals of reducing negative impact on the environment should be achieved (primarily in terms of reducing waste production) and commercial profitability (which is possible by rationalization use of available resources at community level, reuse of waste as secondary raw material), as well as establishment of sustainable interaction between government, business and civil society. 


\section{References}

1. Nechytailo, D. (2020). Blank slate: how it works and how profitable is circular economy. Ekonomichna pravda. https://www.epravda.com.ua/columns/2020/09/2/664626

2. Orlovska, Yu., Yakovyshyna, T., \& Orlovskyi, Ye. (2016). Green building as an element of EU policy of circular economy development. Eastern Europe: Economy, Business and Management, 5(1), 365-371. http://www.easterneuropeebm.in.ua/journal/5 2016/70.pdf

3. Pauli, G. (2010). The Blue Economy: 10 years -100 innovations -100 million jobs: report to the Club of Rome. Paradigm Publications.

4. Serhiienko, L. (2016). Directions of reforming of the state policy in provision of a circular economy in the context of international cooperation. Investytsii: praktyka ta dosvid. 23, 100-110. http://www.investplan.com.ua/pdf/23 2016/24.pdf

5. Struchok, V., \& Mudra, D. (2019) Research of the project of the national waste management plan in Ukraine before 2030 on conducting infrastructure measures for the processing of solid domestic wastes. XXI naukova konferentsiia Ternopilskoho natsionalnoho tekhnichnoho universytetu imeni Ivana Puliuia, 145-147. http://elartu.tntu.edu.ua/bitstream/lib/28196/2/XXI_NK 2019 Struchok VResearch of the project 145-147.pdf

6. Churikanova, O. (2020) Perevahy modeli tsyrkuliarnoi ekonomiky [Advantages of circular economy model]. Topical issues of science and practice. The VII th International scientific and practical conference «Topical issues of science and practice» (November 02-06, 2020). London, Great Britain, p. 151-153.

7. Amosha, O., Pidorycheva, I., \& Zemliankin, A. (2021) Trends in the World Economy Development: New Challenges and Prospects. Science and innovation, 17(1), 3-17. https://doi.org/10.15407/scine17.01.003

8. Ilyash, O., Dzhadan, I., \& Ostasz, G. (2018). The influence of the industry's innovation activities indices on the industrial products' revenue of Ukraine. Economics and Sociology, 11(4), 317-331. https://doi:10.14254/2071-789X.2018/11-4/21

9. Krysovatyy, A., Zvarych, I., \& Zvarych, R. (2018). Circular economy in the context of alterglobalization. Journal of International Studies, 11(4), 185-200. https://doi:10.14254/2071-8330.2018/11-4/13

10. Musova, Z., Musa, H., \& Matiova, V. (2021). Environmentally responsible behaviour of consumers: Evidence from Slovakia. Economics and Sociology, 14(1), 178-198. https://doi:10.14254/2071-789X.2021/14-1/12

11. Zielińska, A. (2019). Comparative Analysis of Circular Economy Implementation in Poland and other European Union Countries. Journal of International Studies, 12(4), 337-347. https://doi:10.14254/2071-8330.2019/12-4/22 